\title{
Pleonastic Explanations
}

MARK SAINSBURY

The Things We Mean, by Stephen Schiffer. Oxford, Clarendon Press 2003. p. 362.

Stephen Schiffer's first book, Meaning (1972), brought Gricean theories of meaning to an unprecedented level of sophistication. Starting with ideas about speaker's meaning sketched by Grice, Schiffer developed in great detail objections, responses to objections, responses to responses to objections, and so on, ending on a generally optimistic note about the viability of an intention-based theory of meaning. His second book, Remnants of Meaning (1987), took a darker turn. Theories of language, one by one, including the theory offered in Meaning, were subjected to very detailed criticisms, and were deemed beyond salvation. All that remained was a 'no-theory theory of meaning', one of whose main tenets was that nothing recognizable as a theory of meaning in the traditional sense was true. In the Introduction to The Things We Mean, Schiffer says that he is now offering a positive theory of meaning: 'What kind of chutzpah is this? Only a mild kind, actually' (9).

The things we mean, says Schiffer, are propositions, like the proposition that nothing travels faster than light, and a prima facie case for this view is given by the 'face value' theory. Propositions are pleonastic entities, entities introduced by 'something-from-nothing transformations', of which the leading examples are fictional characters. Special features of pleonastic entities are said to explain the nature of linguistic understanding, vagueness, morality, conditionals, and the possibility and value of our knowledge of the propositional attitudes of others. This is a wide-ranging and demanding book, covering a vast range of topics of interest to philosophers of language and others. In this review, I have chosen to concentrate on a small part of the book, choosing two issues relating to its framework ((1) the face value theory and (2) the nature of pleonastic entities), and two applications of this framework that I think will attract attention ((3) moral judgements and (4) vagueness). Among the larger parts that it would have been good to discuss are the 
account of understanding in chapters three and four, and the intriguing discussion of conditionals (chapter seven); among the smaller ones is the convincing short section (135-55) on two-dimensional semantics.

\section{The face value theory}

According to the face value theory, a sentence of the form ' $A$ believes that $S$ ' has the form $R a b$, and is true iff 'the referent of the term " $A$ " stands in the belief relation to the proposition to which the "that $S$ " term refers' (12). Initial evidence for the theory comes from such inferences as this:

Harold believes that there is life on Venus and so does Fiona.

So, there is something that they both believe-to wit, that there is life on Venus.

Harold believes everything that Fiona says.

Fiona says that there is life on Venus.

So Harold believes that there is life on Venus.

There are other inferences in the same vein. They are supposed to provide a prima facie case for both a metaphysical conclusion (that belief is a relation to propositions) and a semantic conclusion (that 'that $S$ ' expressions are singular terms referring to propositions). Similar inferential patterns would favour one kind of conclusion rather than the other:

Harold goes to market and so does Fiona.

So, there is something that they both do- to wit, go to market.

Harold does everything that Fiona does.

Fiona goes to market.

So Harold goes to market.

We may incline to the metaphysical conclusion that acting is a relation between an agent and an action, but no one would consider that 'goes to market' is a singular term referring to an individual action. ${ }^{1}$ In other superficially similar cases, the semantic conclusion is made appealing, but not the metaphysical one. For example:

\footnotetext{
${ }^{1}$ Schiffer says that one can infer sentences containing reference to events from sentences which appear not to, and cites 'Jane was born on a Tuesday, so Jane's birth was on a Tuesday' (63). The example is a special case, since people can be born at most once; it does not ground the more general conclusion.
} 
Harold weighs 150 pounds and so does Fiona.

So, there is something that they both weigh - to wit, 150 pounds.

Harold weighs just what Fiona weighs.

Fiona weighs 150 pounds.

So Harold weighs 150 pounds.

No doubt ' 150 pounds' refers to 150 pounds, but we may be much less inclined to suppose that weight is a relation between an object and 150 pounds. Weight (or at least rest mass) is a paradigm of a monadic and intrinsic property.

The face value theory would be more compelling if we had an explanation of the general conditions under which the relevant inferences deliver the desired conclusions (both metaphysical and semantic). The relevant inferences will run in both directions, so the very first question, one which Schiffer does not mention, is why we should regard them as showing that there really are such entities as properties and propositions, rather than using the other direction of inference (the Quinean one) to conclude that there are no such entities. There are also more detailed difficulties. The face-value theory appears to endorse substitution inferences that are incorrect for some of the constructions traditionally classified as idioms of propositional attitude. There are cases in which substituting 'the proposition that $S$ ' for the supposedly coreferential 'that $S$ ' is not guaranteed to preserve truth, for the substitution can 'change the meaning drastically' (93) as in:

Jane fears that Slovenia will win the world cup.

Jane fears the proposition that Slovenia will win the world cup.

And there are cases in which the substitution fails to preserve grammaticality, as in:

Jane hopes that Slovenia will win the world cup.

Jane hopes the proposition that Slovenia will win the world cup.

To infer from these failures that 'the proposition that $S$ ' does not have the same referent as 'that $S$ ' is, Schiffer says, a 'confusion' (93). He shows that there are special idioms in which the substitution of uncontroversially coreferential expressions fails to preserve grammaticality:

The Italian singer Pavarotti never sings Wagner.

The Italian singer the greatest tenor never sings Wagner. 
Hence the case, based on failures to preserve grammaticality, against the coreference of 'that $S$ ' with 'the proposition that $S$ ' would be complete only if it could be shown that the relevant substitutions did not infringe essentially insignificant grammatical constraints. Schiffer does not provide any examples in which the substitution of uncontroversially coreferential expressions preserves grammaticality but (in an extensional context) does not preserve truth, nor does he offer any theoretical considerations in defence of the face-value theory on this point, so the reader may be left in ignorance of why it is a 'confusion' to suppose that cases like Jane's fear do not tell against the coreference of 'the proposition that $S$ ' and 'that $S$ '.

Russell (1912) distinguished between knowledge by acquaintance and knowledge of truth. To know the proposition that Bismarck was astute is to be acquainted with it, and is different from knowing that Bismarck was astute. One is acquainted with a proposition by being acquainted with all its constituents (together, perhaps, with its logical form). This is necessary but not sufficient for knowing that it is true, that is, in the example, for knowing that Bismarck was astute. The face value theory must either say that this difference is of no significance, or else that it can be done justice to while retaining the doctrine about coreference.

\section{Pleonastic entities}

When a writer of fiction introduces a name (with the normal kinds of intentions appropriate to her task), she thereby creates a fictional character. No one will disagree. Schiffer interprets what has occurred in what I call a 'robust' way: he says that, as a result, a fictional entity 'exists in its own right'; it is an abstract object as much part of the real world as sets or numbers. On Schiffer's view, ' $x$ is a fictional entity' entails ' $x$ is an entity'. On a more austere interpretation of the platitude that novelists create fictional characters, this entailment fails, just as the entailment from ' $x$ is an alleged murderer' to ' $x$ is a murderer' fails. An alleged murderer may not be a murderer, and alleging that there is a murderer in the house does not make it the case that there is an alleged murderer in the house. On the robust view, by contrast, a fictional entity is an entity, and to make up a fiction in which there is a certain character is to bring it about that there is a new entity in the realm of the real, an entity which is the subject of a variety of genuine, and not merely fictional, truths. 'Fictional' qualifies a noun in the straightforward way that adjectives like 'happy' do. On a more austere interpretation, the role of 'fictional' is more like a sentence operator, just as 
adjectival occurrences of 'alleged' are often best understood in terms of 'it is alleged that'. To say that there are fictional characters is, on the austere view, to say no more than that there are fictions according to which there are characters. Those who prefer an austere view will need to put it on the back burner if they are to profit from Schiffer's use of fictional characters to introduce the idea of a pleonastic entity, for the discussion is firmly, though without argument, committed to the robust view.

For fictional characters, the something-for-nothing inference takes you from a writer's pretend use of a name to the existence of a corresponding robust fictional entity. The inference is guaranteed by the supposed conceptual truth 'that the existence of fictional entities supervenes on the pretending use of their names' (52). One cannot always rely on such conceptually based inferences: it may be a conceptual, because stipulated, truth that a wishdate is someone whose existence supervenes on, and is guaranteed by, a person wishing for a date, but we should not infer from wishes for dates to wishdates. The reliable inferences are ones which, roughly speaking, conservatively extend the theory which obtains before the concept in question is introduced. The wishdate inference is not reliable, since mere wishes would unconservatively require revisions to population statistics.

Fictional characters are pleonastic entities created by human activity, but this is not the right way to view all pleonastic entities, even though all of them are closely tied, for their existence, to human activity ('our conceptual practices exhaust what may be true of all properties and propositions' (212)). Properties, though not created, are pleonastic, since it is a conceptual truth they supervene on truths which appear not to mention them. From the statement 'Lassie is a dog' we can infer 'Lassie has the property of being a dog', and so infer that there is at least one property. Schiffer thinks of properties as abundant in the extreme, since there is one for every intelligible predicate (barring a qualification about heterological-style paradoxes), and he endorses Armstrong's (1989) phrase that, on this conception, they are 'mere shadows of predicates' (63). This makes them thin things: 'there isn't a lot more to [the property of being a dog] than can be culled from the something-fornothing transformation' (64), the one from ' $x$ is a dog' to ' $x$ has the property of being a dog. This is not enough, Schiffer claims, for there to be determinately true identity statements like: the property of being a dog is the property of having such-and-such genotype, or the property of being in pain is the property of being in such-and-such neural state. The something-for-nothing transformations do not speak to these 
issues; hence there are no determinate facts of this kind. This is one link between pleonastic entities and indeterminacy.

Propositions are pleonastic entities in virtue of the conceptual truth that we can always move from ' $p$ ' to 'that $p$ is true'. In conformity with the face value theory, the latter sentence is to be parsed as starting with a singular term whose referent is a proposition. We get propositions from truths, in the something-for-nothing way, because there is a transformation that 'takes us from "Lassie is a dog"' to "That Lassie is a dog is true' (71). If I know that Lassie is a dog, I can infer that that Lassie is a dog is true, and so, on the proposed analysis, infer, and thereby come to know, that there is such a proposition as that Lassie is a dog. Are there false propositions? Presumably there should be; but what is false cannot be known, and so we cannot use the pattern of inference just described in order to come to know that there are such things. Maybe we should use the truth schema 'The proposition that $S$ is true iff $S$ ' and argue by dilemma, one horn of which delivers 'The proposition that $S$ is not true, which will be enough to infer (and so come to know, once the rest of the argument is set out) that there is such a thing as the proposition that $S$. Whether arguments by dilemma are valid in the indeterministic logic to which Schiffer subscribes is a question he does not address.

Propositions are shadows of sentences, so adding them 'does nothing to disturb the pre-existing causal order'; they constitute a conservative extension. But they are not so shadowy as properties, since their role in propositional attitudes belongs to their nature but 'is not deducible from the something-for-nothing practice' (72). Examining propositional attitudes, Schiffer reaches the conclusion that they are relations to 'unstructured but very fine-grained propositions' (84), and he goes on to explain this departure from the less ontologically robust view he had taken earlier (in Remnants).

A salient feature of Schiffer's pleonastic propositions is that the 'that $S$ ' singular terms which refer to them do so in an 'importantly different' way from the way in which normal singular terms refer to their referents. In the normal case, competent speakers bring their knowledge of the referent of a referring expression to bear when trying to determine whether a sentence containing it is true or false. In the special case of 'that $S$ ' expressions, Schiffer says that this is not always so. We know that 'Lois believes that Superman flies' may differ in truth value from 'Lois believes that Clark Kent flies' 'and on this basis we know that the proposition that Superman flies $\neq$ the proposition that Clark Kent flies' (77). The idea is that we come to individuate propositions only on the 
basis of their occurrence in belief ascriptions, but it is not clear that the argument establishes this. We might not know whether the proposition that Clark Kent flies is the same as or different from the proposition that Superman flies while knowing what proposition each is, just as we can know which person Tully is and which person Cicero is without knowing whether they are the same or different, or which person Strawson (Peter) is and which person Strawson (Galen) is without knowing that they are different. Even so, Schiffer's argument might establish that there was something special about 'that $S$ ' clauses if it established that we can test them for coreference by embedding them, but that we cannot do this for ordinary referring expressions. Concerning the pair 'Henri admires Picasso' and 'Henri admires Braque', Schiffer invites us to consider 'the absurdity of supposing that we know that Picasso ${ }_{\lambda}$ Braque because we know that the statements [just mentioned] may differ in truth value' (73). The example is a little confusing because of the seeming non-extensionality of 'admires' (it seems that one may admire Tully without admiring Cicero). But for ordinary extensional cases, the supposedly absurd pattern of inference, or something very like it, is commonplace. If we find that 'The murderer wears size 10 shoes' and 'Jack wears size 10 shoes' actually differ in truth (which implies that they can differ in truth value) we are happy to infer the distinctness of Jack and the murderer. What does the work in such a case is actual difference of truth value, whereas Schiffer's point was made in terms of merely possible difference of truth value; so perhaps the criticism misses the mark. What emerges is a somewhat different difference between 'that $S$ ' referring expressions and others. On ordinary post-Kripke assumptions, identities are necessary, so the metaphysical possibility of distinctness is enough for the actuality of distinctness. In the case of Lois's beliefs about Kent/Superman, we know a priori that there is a possible difference in truth value, and so a possible difference in referent for the 'that $S$ ' clauses, and so an actual difference in referent. In the case of Jack and the murderer, we have no such apriori knowledge of possible distinctness. Possible distinctness could only be inferred from actual distinctness. So the real difference which emerges is simply that we often have apriori knowledge of sameness and difference among propositions.

\section{Moral realism}

In chapter six, Schiffer agrees with cognitivists that there are such things as moral propositions, pleonastic ones, of course; but concedes 
to non-cognitivists that 'there are no determinate moral truths' (238). Hence there is no moral knowledge (so it may be confusing that he allows his position to be called cognitivist). His discussion presents some brilliantly clear arguments, yet the conclusion seems to me one which few will accept, for it entails that we are in error if we confidently believe that torturing children for fun is morally wrong.

Schiffer admits that if the indeterminacy of moral propositions were generally appreciated, moral debate as we now know it would end. The best philosophers, as Yeats might have said, would lack all conviction. Rather than disagree about whether, say, the death penalty is morally legitimate, we would agree that this is an issue on which we should have no conviction, and something we should not, indeed could not, sensibly dispute, since it is known to be indeterminate. Schiffer thinks this upshot is not as absurd as it sounds, for there would still be room for us to agree or disagree on what we wanted and wanted others to want, and moral words might serve as 'quick and easy ways' (261) to mark these things out. 'We don't need morality to keep us from torturing children for the fun of it' (251). Although he is firmly of the opinion that moral education can and should help to shape or curb desires (personal communication), it is hard to see how the official doctrine allows for this. At a minimum, such education would need to draw a veil over the facts that none of the moral opinions, the instilling of which is supposed to shape desires, are determinately true, and that no one whose metaphysics was correct should have any confidence in these opinions.

How does the doctrine of pleonastic entities help explain the existence, but indeterminacy, of moral propositions? Schiffer provides two arguments for the existence of moral propositions. ${ }^{2}$ One is based on applying the face value theory to truths like 'Sally believes that eating animals is wrong'. The other is that 'moral sentences embed in sentences that evidently have truth values' (240) and this requires them to express propositions. Let us grant this (passing over Schiffer's detailed and nuanced discussion of opposing arguments), and press more closely on the explanation for the indeterminacy.

There are two issues in play. One is that it is, supposedly, possible to be ambivalent about any moral proposition even though one is in an epistemically ideal position to know that it is true (if it is true) or false

\footnotetext{
${ }^{2} \mathrm{He}$ lists four. The first (the inference from 'Eating animals is wrong' to 'It is true that eating animals is wrong') is not available in the dialectical context, since using it to extract knowledge that there are moral propositions requires knowledge of the premiss, which is just what is in dispute (and Schiffer's own view is that we do not have this knowledge). The fourth listed reason is that 'whatever reasons there are for accepting [the theory of pleonastic propositions] are ipso facto reasons for thinking there are moral propositions' (240).
} 
(if it is false); this alone is enough to ensure that all moral propositions are indeterminate (254). The other is that the application of moral concepts is taken to supervene at least in part on conative facts; this is why moral concepts do not have determinate applications (257-8).

The relevant ambivalence is an attitude that Schiffer describes in more detail in his chapter on vagueness (chapter five). It is a special kind of partial belief, referred to as a VPB (a Vagueness-related Partial Belief (201)). The general principle is that if any rational person can VPB a proposition, while also being in a state epistemically ideal with respect to the proposition, the proposition is indeterminate. This is exemplified by the possibility that someone who has full information about the number of hairs on Tom's head should be ambivalent about whether Tom is bald. That there could be such a person is enough to establish that it is indeterminate whether Tom is bald. Likewise, Schiffer urges, for any moral principle, an ideally rational person may be in such a state of partial belief about the proposition (254). Hence all moral principles are indeterminate. This argument draws on Schiffer's earlier discussion of vagueness, and will be considered below $(\$ 4)$.

The argument special to morality is based on one or more supervenience claims, in which conative states are said to feature among what is subvenient. Those who believe in moral properties typically believe that their distribution supervenes on non-moral properties: necessarily, things that differ in moral properties also differ in non-moral properties. Schiffer, however, has a stronger supervenience principle in mind: 'It belongs to our moral concepts that their application must supervene on the application of some non-normative concept' (257). When Schiffer speaks of 'application', I presume he does not mean to claim that acts of applying moral concepts supervene on acts of applying non-moral ones: someone could apply a moral concept to something without also applying a non-moral one, and this possibility ensures that there could be things which differ in which moral concepts have been applied to them but not with respect to which non-moral concepts have been applied to them. Schiffer may intend a normative version of this claim, perhaps to this effect: if one can justifiably apply a concept to just one of two things, there is a non-moral concept which one can justifiably apply to just one of the things. This would probably receive widespread support, but Schiffer's dialectic requires something somewhat different: that if ever a thinker applies a moral concept to something, there are non-normative conditions which, perhaps implicitly, the thinker takes to be sufficient for the application of the moral concept to be correct (257, same paragraph as sentence recently 
quoted). In other words, Schiffer holds that belief in a conditional which states how the moral supervenes on the non-moral is implicated in every moral judgement.

An even stronger doctrine is explicitly formulated: if there is moral truth there are knowable, and known, 'moral principles' (that is, supervenience conditionals: necessarily true propositions of the form 'whatever has $\varphi$ has $M^{\prime}$ ' $\varphi$ a non-normative property, $M$ a moral property) (245-6)). Everyone who believes in supervenience believes there are true moral principles (in this sense), but it is consistent to hold that we have moral knowledge without knowledge of these truths. This is the position taken by particularists (Jonathan Dancy is a notable example). They hold that moral knowledge starts with particular cases. We may have qualified beliefs in generalizations, but we realize that these are at best useful rules of thumb (like 'Lying is wrong'), expediting decisions under stress or uncertainty, rather than exact truths. We can usually think of exceptions to generalizations, and even if we cannot, we are right to be cautious about them. This does not undermine proper confidence in moral judgements concerning particular cases; generally, we are much more confident that a particular action is right or wrong than we are of how to generalize this judgement. The position is consistent with the supervenience of the distribution of moral properties on that of non-normative properties. It is also consistent with the controversial claim that justifying a moral opinion concerning some action requires one to cite at least one of its non-normative features. What it denies is that we can or need to know the relevant supervenience conditionals, the 'moral principles'.

Consider the following analogy. Many theorists agree that the mental supervenes on the physical in that there cannot be a mental difference without a physical difference. Some of these theorists may also hold, controversially, that justifying an opinion concerning a mental property of a person, for example the opinion that Sally is in pain, requires one to cite at least one non-mental property of that person, for example that Sally is crying and her toe is bloody. All this is consistent with the claim that we have some justified beliefs, indeed knowledge, concerning who has what mental properties without knowing any supervenience conditionals. We know quite well that though Sally is in pain, not everyone who cries and has a bloody toe is in pain.

The main thrust of Schiffer's explanation of the special nature of moral properties and propositions, however, does not depend on whether we have knowledge of moral principles. Rather, it depends upon the supposedly conative elements in the subvenient non-norma- 
tive properties. The official doctrine is that this base consists in the application of concepts for conative properties, but as far as I can see the explanation would not be substantially different if Schiffer were to think of the base as simply the conative properties themselves. How do these induce indeterminacy? It seems unlikely that the answer can be in terms of indeterminacy in what each person wants. The crucial point is said to be that we want different things (256, reinforced by a personal communication), but it remains to be explained how this leads to indeterminacy. The value of a stock market index (like the Dow Jones) supervenes upon the value of the underlying stocks. These subvenient values may move in different directions without inducing any indeterminacy in the index.

\section{Vagueness}

New theories of vagueness are not abundant, and Schiffer's chapter on this subject is likely to be widely discussed. He claims that rather than being semantic, epistemic or ontological, vagueness is a psychological phenomenon. It arises from the special kinds of partial beliefs already mentioned: VPBs, or vagueness-related partial beliefs. These come in degrees which can, under idealization, be described in terms of numbers between 0 and 1 , and they are to be distinguished in various ways from degrees of belief in the sense of subjective probability, s-beliefs. VPBs do not mark ignorance, 'we couldn't have VPBs if our language were perfectly precise', and complex VBPs combine differently from the way in which subjective probabilities combine (in the manner of Lucasiewicz rather than Kolmogorov).

Schiffer proposes to define borderline cases, and hence vagueness, in terms of VPBs: at a first approximation, an object $x$ is a borderline case with respect to $F$ iff someone in ideal epistemic conditions (which include that the person 'is ideally rational in the relevant respects' (209)) could believe to some intermediate degree that $x$ is $F$ (210; the final version, labelled (E), is on 212, and is displayed and discussed below). It is not that VPBs track the property of being borderline; rather they constitute what it is to be borderline (211). That is what makes vagueness a psychological phenomenon. If VPBs tracked being borderline, being borderline would be a phenomenon which is in some sense independent of VPBs. The tracking view would introduce a 'third possibility', which, following Crispin Wright, Schiffer rejects. On third possibility views, indeterminacy (or being borderline) is a 'kind of determinate truth status ... contrasting with both the poles (truth 
and falsity)' (Wright quoted by Schiffer on 191). If VPBs tracked being borderline, then, in ideal epistemic conditions, having a VPB would be the unique rational response to a borderline case, which would ensure that the case contrasts with both truth and falsity, and so would constitute a 'third possibility'. This means that when Schiffer defines being borderline in terms of the possibility of someone having a $\mathrm{VPB}^{\star}$ (that is, a VPB formed under ideal epistemic conditions), he cannot include being a good tracker of borderlineness as part of what it is for a subject to be rational. How does the rationality requirement work out?

Schiffer invites us to consider a possible situation in which Tom's hairs are plucked out one by one. Sally, a rational speaker of English, observes the process closely. She 'starts out judging with absolute certainty that Tom is not bald ... At some point, however, Sally's judgement that Tom isn't bald will have an ever so slightly diminished confidence, reflecting that she believes Tom not to be bald to some degree barely less than 1 . The plucking continues and as it does the degree to which she believes Tom not to be bald diminishes ...' (203). Schiffer envisages the changing degrees of VPBs to be reflected in 'qualified judgements', though we are not told what the qualifications are (whether they qualify the confidence as in 'I am not sure but I think maybe he is not bald' or the content as in '(I am sure) he is verging on bald'). Why should a rational person respond like Sally? Why should she not just become confused, making no assertions or judgements for quite a while? Why might not questioning result in stony silence or protestations of ignorance? Why should she not fail to form any 'settled disposition' (216) to judge? Why should she not judge without qualification that Tom is not bald until the last hair is pulled out, and then switch to the other judgement? Why should she not, given some suitable further aim, simply make a completely legitimate ruling, local to the particular case or just to cases resembling it in terms of the aim in question, on when Tom is to count as bald? Schiffer does not say. Although he says that Sally's responses may vary in small ways without prejudice to her rationality (214), he does not consider more radically distinct alternative responses. He cannot rule these irrational on the grounds of their being rationally inappropriate to borderlineness. This would presuppose that Sally's responses, if rational, should track the phenomenon of borderlineness, whereas Schiffer's theory is that the responses constitute the phenomenon: 'When the sentence 'Tom is bald' goes into Sally's VPB box, it is not as a response to her perception of the independently explicable fact that he's a borderline case of baldness' (212). 
Compare Schiffer's position with a theory according to which beauty is 'response-dependent': the property is constituted by the fact that people respond to things which possess it in a distinctive way. Could a theorist of this ilk require that we should consider only the responses of people who are 'ideally rational in the relevant respects', so that, for example, people who do not get the distinctive response in the presence of Michelangelo's David thereby count as irrational? This may not be an impossible path but it is certainly a treacherous one. The alleged irrationality cannot consist simply in the fact that the subject did not evince the statistically more common response. Some independent failure needs to be identified.

Schiffer might say that it is irrelevant to his theory that rational responses very different from Sally's are possible. All his theory requires is that Sally's is one possible way for a rational person to behave. The existence of this possibility is what constitutes vagueness, regardless of what other possibilities there are. The difficulty with this approach is that we need some explanation for selecting Sally's responses, rather than others, as guides to the nature of vagueness. In setting out the finished definition of a borderline case, Schiffer narrows appropriate responses in the direction of Sally's kind rather than the others:

one's $\mathrm{VPB}^{\star}$ that $x$ is $F$ is F-concept-driven when one is in ideal circumstances for judging $x$ to be $F$ and one's concept of being $F$ precludes one from s-believing to any positive degree either that $x$ is $F$ or that $x$ is not $F$ and determines one to v-believe to some positive degree that $x$ is $F$. Then we can say that:

(E) $x$ is a borderline case of being $F$ iff someone could have an $F$-concept-driven $\mathrm{VPB}^{\star}$ that $x$ is $F$. (212)

Schiffer must deny the following:

if $x$ is $F$, nothing in the concept of being $F$ precludes one from s-believing to a positive degree that this is so.

For if $x$ is borderline for $F$, something in the concept of being $F$ precludes one (according to (E)) from s-believing that $x$ is $F$, so, granted the displayed principle, one would have to conclude that $x$ is not $F$; being borderline would be a clear third possibility. Classically, to deny the principle is to assert that there is at least one $F$ which something in the concept of being $F$ precludes one from s-believing to be $F$. Our concepts preclude s-belief in some cases in which our epistemic situation is optimal and the belief would be true. This suggests that 'conceptual' 
rather than 'psychological' might be the best name for Schiffer's claimed source of vagueness. In this perspective, what needs explaining in terms of our psychology is the quirk that draws us to form such strange concepts. Any explanation of vagueness needs to mention our limited powers of discrimination and the fact that many properties of interest to us come in degrees which are apparently, or effectively, continuous. It is not clear how one can tie such platitudes to Schiffer's appeal to psychology as the source or essence of vagueness.

Those who, like Carneades, respond to borderlines by silence (or professions of ignorance, or confusion, or ruling, or anything other than a v-belief) must be said not to be masters of the relevant concepts or else not fully rational. Call a thinker a thinker* if she is fully rational, is master of the concept $F$ and is confronted by a borderline case for $F$ under ideal epistemic conditions. For Schiffer, this means that there could be an F-concept-driven $\mathrm{VPB}^{\star}$ to the effect that $x$ is $F$. So there could be a thinker*, someone who is 'precluded' from forming s-beliefs and 'determined' to form v-beliefs. At first it might seem that this is consistent with there also being another thinker*, say Carneades, who fails to form v-beliefs in the presence of borderline cases for $F$. We might think the right analogy is with the clearly consistent claim that it is possible that there be something happy and also possible that there be something not-happy. But this is not right. The possibility relates to there being someone in the position of a thinker* ${ }^{*}$ rational, master of the concept, and confronted with a borderline case for it. It is in virtue of being a thinker ${ }^{\star}$ that one is precluded from forming s-beliefs and determined to form v-beliefs, so Schiffer is committed to saying that, quite generally, fully rational thinkers who confront a borderline case for $F$ and who are masters of $F$ are precluded from forming s-beliefs and determined to form v-beliefs. Since Carneades does not form a vbelief concerning $x$ being $F$, he is either not master of the concept $F$ or else not fully rational. Since his response seems to me an eminently rational one for a master of a vague concept, I cannot accept Schiffer's account of vagueness. ${ }^{3}$

\footnotetext{
${ }^{3}$ Thanks to members of a Reading Group at King's College London with whom I discussed Schiffer's book in the summer of 2004, especially Scott Sturgeon; and to Stephen Schiffer for comments and clarifications.
} 
Department of Philosophy

R. M. SAINSBURY

University of Texas at Austin

USA

Department of Philosophy

King's College London

UK

marksainsbury@mail.utexas.edu

\section{References}

Armstrong, D. 1989: Universals: An Opinionated Introduction. Boulder: Westview Press.

Dancy, J. 2004: Ethics Without Principles. Oxford: Oxford University Press.

Russell, B. 1912: Problems of Philosophy. Oxford: Oxford University Press (1959).

Schiffer, S. 1972: Meaning. Oxford: Oxford University Press.

Schiffer, S. 1987: Remnants of Meaning. Cambridge, MA: MIT Press.

Wright, C. 2001: 'On being in a quandary: relativism, vagueness, logical revisionism'. Mind, 110, pp. 45-98. 
